\title{
Evaluation of the performance of a particle concentrator for online instrumentation
}

\author{
S. Saarikoski ${ }^{1,2,3}$, S. Carbone ${ }^{1}$, M. J. Cubison ${ }^{2,3, *}$, R. Hillamo ${ }^{1}$, P. Keronen ${ }^{4}$, C. Sioutas ${ }^{5}$, D. R. Worsnop ${ }^{1,4,6}$, and \\ J. L. Jimenez ${ }^{2,3}$ \\ ${ }^{1}$ Atmospheric Composition Research, Finnish Meteorological Institute, 00101, Helsinki, Finland \\ ${ }^{2}$ Cooperative Institute for Research in the Environmental Sciences, 80309, Boulder, USA \\ ${ }^{3}$ Department of Chemistry and Biochemistry, University of Colorado at Boulder, 80309, Boulder, USA \\ ${ }^{4}$ Department of Physics, University of Helsinki, Post Office Box 64, 00014, Helsinki, Finland \\ ${ }^{5}$ Department of Civil and Environmental Engineering, University of Southern California, Los Angeles, CA, 90089, USA \\ ${ }^{6}$ Aerodyne Research Inc., Billerica, MA 01821, USA \\ *now at: Tofwerk AG, 3600 Thun, Switzerland
}

Correspondence to: S. Saarikoski (sanna.saarikoski@fmi.fi)

Received: 8 February 2014 - Published in Atmos. Meas. Tech. Discuss.: 21 March 2014

Revised: 27 May 2014 - Accepted: 28 May 2014 - Published: 15 July 2014

\begin{abstract}
The performance of the miniature Versatile Aerosol Concentration Enrichment System (m-VACES; Geller et al., 2005) was investigated in laboratory and field studies using online instruments. Laboratory tests focused on the behavior of monodisperse ammonium sulfate (AS) or dioctyl sebacate (DOS) particles in the m-VACES measured with the aerodynamic particle sizer (APS) and scanning mobility particle sizer (SMPS). The ambient measurements were conducted at an urban site in Helsinki, Finland, where the operation of the m-VACES was explored in conjunction with a Soot Particle Aerosol Mass Spectrometer (SP-AMS) in addition to the SMPS. In laboratory tests, the growth of particles in water vapor produced a stable droplet size distribution independent of the original particle size. However, when the droplets were dried with the goal of measuring the original size distribution, a shift to larger particles was observed for small particle sizes (up to $\sim 200 \mathrm{~nm}$ in mobility diameter). That growth was probably caused by watersoluble organic compounds absorbed on the water droplets from the gas phase, but not evaporated in the drying phase. In ambient measurements, a similar enrichment was observed for nitrate and sulfate in the m-VACES whereas the presence of acidic ambient particles affected the enrichment of ammonium. Gaseous ammonia was likely to be absorbed on acidic particles in the m-VACES, neutralizing the aerosol. For organics, the enrichment efficiency was comparable with
\end{abstract}

sulfate and nitrate but a small positive artifact for hydrocarbons and nitrogen-containing organic compounds was noticed. Ambient and concentrated organic aerosol (OA) was analyzed further with positive matrix factorization (PMF). A three-factor solution was chosen for both of the data sets but the factors were slightly different for the ambient and concentrated OA, however, the data set used for the PMF analysis was limited in size (3 days) and therefore had substantial uncertainty. Overall, the operation of the m-VACES was not found to lead to any severe sampling artifacts. The effect of acidity could be an issue in locations where the aerosol is acidic, however, in those cases the use of a denuder (which was not used in this study) is recommended. Further ambient tests are needed for the characterization of the m-VACES as the time period for the ambient measurements was only 5 days in this study. Especially for OA additional tests are important as the chemical properties of organics can differ widely depending on time and location.

\section{Introduction}

Atmospheric aerosols have significant impacts on human health as they are deposited within the respiratory system (e.g., Dockery et al., 1993), and on climate by scattering and absorbing solar radiation (Charlson et al., 1992) or changing 
Earth's surface albedo after deposition on snow (Ramanathan and Carmichael, 2008). Quantifying the climate and health effects of atmospheric aerosols needs rapid and detailed information of the aerosol chemical composition as a function of particle size. Advanced online measurements developed over the last decade, such as the aerosol mass spectrometer (AMS; Canagaratna et al., 2007) enable almost real-time extraction of aerosol chemical composition. Their fast response has allowed a more precise characterization of aerosol sources and processes. The performance of online methods, such as the AMS, can be extended to lower concentrations, higher time or mass resolution, or to soft-ionization if the typical atmospheric aerosol concentrations are increased by using a particle concentrator upstream of these spectrometers. In general, particle concentrators improve online instrument performance in two basic ways: they enable shorter integration times (Dreyfus et al., 2008; Sun et al., 2009), and/or new compounds may become detectable when the particulate mass available for analysis increases (Salcedo et al., 2010, 2012).

In the past, particle concentrators were used mainly for health exposure studies in order to collect a large amount of particulate matter on filters for laboratory assays (e.g., Cho et al., 2005) or for direct inhalation exposure studies (e.g., Sioutas et al., 1997; Gupta et al., 2004). Additionally, it has been suggested that the use of particle concentrators can improve the operation of particle samplers by reducing evaporative losses from particles collected on either impactor substrates or filters (Chang et al., 2000). Many designs of particle concentrators are based on virtual impaction (VI; Willeke and Baron, 1993), in which the particles larger than a certain size are concentrated by using inertial separation (e.g., Sioutas et al., 1997; Demokritou et al., 2003). However, in traditional concentrators, enrichment of particles with diameters smaller than a few hundred nanometers is very difficult to achieve due to the high pressure drop needed across the VI. The use of a virtual impactor with moderate pressure drop is possible by growing particles prior to VI by condensation of water vapor. In this approach, submicron particles grown to $2-4 \mu \mathrm{m}$ droplets are separated from the sample flow by using a virtual impactor, excess water from the droplets is removed e.g., by a drier, and ideally each particle returns to its original size. This technique has been used e.g., in the Versatile Aerosol Concentration Enrichment System (VACES; Kim et al., 2001a, b), miniature VACES (m-VACES; Geller et al., 2005) and in the Harvard Ultrafine Concentrated Ambient Particle System (HUCAPS; Gupta et al., 2004).

A critical requirement for an operational aerosolconcentrating system is the homogeneous enrichment of each particle size and chemical species of the aerosol distribution. In condensational growth concentrators, like VACES and HUCAPS, the condensation of water and the changes in air temperature could alter the chemical composition of particles and the size distribution due to condensation of species that remain in the particles after water evaporation, and/or coagulation of particles and/or water droplets. Multiple studies are available in the literature where the concentrator systems are tested for such artifacts. Typically, the particle size is unaffected for larger particles but a shift of small particles to larger sizes has been observed. Such a size shift has been observed e.g., for the HUCAPS (Su et al., 2006; Rastogi et al., 2012), however, for the m-VACES only a minimal distortion of the size distribution was detected (Ning et al., 2006) and for the VACES there was no indication of a shift in the size distributions (Freney et al., 2006).

Regarding the chemistry of particles, both inorganic and organic artifacts have been associated with concentrators. For the VACES, Khlystov et al. (2005) found that there was a positive artifact for nitrate during polluted days whereas for sulfate and organics the artifact was very minor. A thermodynamic model predicted that the formation of nitrate in the VACES depended on ammonia concentrations; the artifact should be more pronounced in ammonia-limited conditions and nearly undetectable in ammonia-rich conditions. In several other studies using the VACES, there were no detectable changes in the chemical composition of particles during the concentrating process (Kim et al., 2001a, b; Zhao et al., 2005; Freney et al., 2006). Similarly to the VACES, no major artifacts in chemistry have been observed for the m-VACES (Ning et al., 2006).

Jung et al. (2010) investigated gas phase artifacts in the VACES by studying highly soluble vapors, hydrogen peroxide, ammonia and nitric acid. Their results indicated that there were two processes associated with the gases in the VACES; gases can be absorbed into the particles as they grow with the condensation of water or they can be lost to condensed water mostly in the saturator. Nitric acid and hydrogen peroxide were found to be lost in the saturator water whereas ammonia was absorbed into particles, the relative importance of these processes following the order of Henry's law solubilities.

Compared to the VACES and m-VACES, HUCAPS appears to have more artifacts associated with the concentrating process. Su et al. (2006) noticed that in the HUCAPS elemental carbon particles were coated by water-soluble organics that had been originally in the ultrafine range. Furthermore, aromatic and polycyclic aromatic hydrocarbons (PAHs) were enriched in the ultrafine region $(50-100 \mathrm{~nm})$ but amines were decreased downstream of the HUCAPS, possibly due to volatilization losses during the drying process. In contrast to the HUCAPS, in the VACES an increase of amine-type particles was observed in fine particles (100$300 \mathrm{~nm}$ ) but there was no significant change in PAHs (Su et al., 2006). Also McWhinney et al. (2012) reported significant organic artifacts in the HUCAPS, and they speculated that nitrate may also be lost in the HUCAPS system. Artifacts associated with the operation of particle concentrators need to be evaluated carefully regardless of whether the concentrator is used for toxicological studies, source apportionment, identification of new compounds or some other purposes in 
which the chemical and physical properties of concentrated aerosol affect the outcome of the study.

This study expands on previously published evaluations of the performance of the m-VACES in laboratory and field measurements. The present paper complements the laboratory studies of Geller et al. (2005), and the field evaluation studies of Ning et al. (2006) by using a soot particle aerosol mass spectrometer (SP-AMS) capable of measuring the aerosol size distribution and detailed chemical composition in a time resolution of few minutes. The aim of this study was to investigate (1) the enrichment efficiency of particulate chemical species in the m-VACES, and the factors affecting the enrichment efficiency; (2) the change in the original aerosol chemical properties during the concentrating process; (3) possible artifacts associated with the operation of the m-VACES; and (4) new species that are undetectable without the concentrator system.

\section{Experimental methods}

\subsection{Miniature VACES (m-VACES)}

The miniature VACES used in this study was similar to that presented in Geller et al. (2005). The design and operation of the m-VACES is described here only shortly as it is explained in detail in previous publications. m-VACES is a miniature version of original VACES design, with lower "intake" and "minor" flow rates (30 and 1-1.5 Lpm (liters per minute), respectively) than the original VACES. The humidification of the air stream is achieved with a saturator consisting of a heated and wetted commercially available cellulose sponge surrounding the intake flow. Cooling the aerosol flow, in order to reach water supersaturation state and thus strong particle growth, is accomplished using a commercially available, solid-state, thermo-electric chiller. Cooling temperature is higher in the $\mathrm{m}$-VACES $\left(-1^{\circ} \mathrm{C}\right)$ than in the original VACES ( -6 to $-8^{\circ} \mathrm{C}$ ) eliminating the buildup of ice on the inner walls of the condenser tube. After growing to larger sizes, the aerosol is concentrated using a small virtual impactor and then dried to the original size using a diffusion dryer filled with silica gel.

In this study, the m-VACES was used in the laboratory and in the field. Operational parameters used in the m-VACES were quite similar to those employed in Geller et al. (2005) and Ning et al. (2006). Inlet flow for the m-VACES was 30$31 \mathrm{Lpm}$ and the minor flow 1-1.1 Lpm. Temperature downstream from the saturator was $35-37^{\circ} \mathrm{C}$ in the laboratory measurements and $30^{\circ} \mathrm{C}$ in ambient measurements, which was slightly higher than suggested in Ning et al. (2006) ( 4$7^{\circ} \mathrm{C}$ above ambient temperature). At lower saturator temperatures there was no enrichment of particles, which could have been due to the very low relative humidity of the sample air (especially in the laboratory). It has been reported earlier that if ambient conditions are relatively warm, dry and/or clean, the saturator temperature needs to be increased (Ning et al., 2006). Chiller temperature was set at -3 to $-2{ }^{\circ} \mathrm{C}$, which was $1-2^{\circ}$ degrees lower than suggested in Geller et al. (2005). Silica gel in the dryer was changed every few days based on the change in the color of the gel. Enrichment factor (EF) in the m-VACES was calculated as the ratio of aerosol number/mass concentration after the m-VACES to that without the m-VACES.

\subsection{Laboratory setup}

Laboratory experiments were carried out at the Finnish Meteorological Institute in Helsinki, Finland, in February 2010. m-VACES was tested with a water condensation particle counter (W-CPC; TSI, Model 3785), electrostatic classifier (TSI, model 3080) with differential mobility analyzer (DMA, TSI, Model 3081), and aerodynamic particle sizer (APS; TSI Model 3320).

For laboratory experiments submicrometer particles $(0.01-1 \mu \mathrm{m})$ were generated with a constant output atomizer (TSI, model 3076) from dioctyl sebacate (DOS) in 2propanol and from ammonium sulfate (AS) in deionized water. Generated particles were dried with a silica gel dryer and the desired monodisperse particle size fraction was selected by using the DMA.

Droplet size distributions downstream of the m-VACES without the dryer were measured with the APS from $\sim 0.5$ to $20 \mu \mathrm{m}$ (aerodynamic diameter) with a time averaging of 1 minute. After employing a silica gel dryer, the particle number-size distribution before and after the m-VACES was obtained by using a scanning mobility particle sizer (SMPS) which consisted of an electrostatic classifier with DMA and W-CPC. The SMPS measured with a time resolution of 3 minutes scanning from 15 to $420 \mathrm{~nm}$ (mobility diameter).

\subsection{Ambient measurements}

\subsubsection{Measurement site}

Ambient measurements were carried out at the Station for Measuring forest Ecosystem-Atmosphere Relations (SMEAR) III in Helsinki, Finland (Järvi et al., 2009), in 5 days from 9 to 14 April 2010. SMEAR III is located at the University of Helsinki campus area about $5 \mathrm{~km}$ northeast from the city center of Helsinki. Buildings of the Finnish Meteorological Institute and University of Helsinki are located next to the station. About $200 \mathrm{~m}$ east from the station there is a major road with heavy traffic, and a small forested area between the road and the station. In addition to traffic, also biomass combustion for residential heating is a source of submicron particles at SMEAR III (Saarikoski et al., 2008). It is also possible that there was a small fraction of crustal material in the particles, even though only submicron sizes were investigated, as the measurements were carried out in springtime when road dust is typically resuspended. 
The performance of the m-VACES was studied by using a SP-AMS for aerosol chemical species and SMPS for particle number and volume distributions. There were two sampling lines, one for the m-VACES and a second one for the bypass flow, that were switched every 30 minutes with solenoid valves. Both sampling lines used the same $\mathrm{PM}_{10}$ inlet on the roof of the measurement station.

\subsubsection{SP-AMS}

The soot particle aerosol mass spectrometer (Aerodyne Research Inc., USA; Onasch et al., 2012) is a combination of two well-characterized instruments: the Aerodyne high resolution time-of-flight aerosol mass spectrometer (HR-ToFAMS; DeCarlo et al., 2006) and the single particle soot photometer (SP2; Droplet Measurement Technologies, CO, USA). In the SP-AMS, an intracavity Nd:YAG (neodymiumdoped yttrium aluminium garnet) laser vaporizer $(1064 \mathrm{~nm})$, based on the design used in the SP2 instrument, is incorporated into the HR-ToF-AMS. The addition of the laser enables the vaporization of refractory particles, specifically laser-light absorbing refractory black carbon (r-BC) and some metal particles that are not detected in the standard AMS. The laser vaporizer does not interfere with the standard tungsten vaporizer used in the HR-ToF-AMS instrument or generate any ions as the photon energy is much below species ionization potentials. Therefore, the SP-AMS instrument can be operated with the laser vaporizer alone, with both the laser and tungsten vaporizers, or just with the tungsten vaporizer. If the SP-AMS has both the tungsten and laser vaporizers it measures refractory black carbon and associated non-refractory particulate material in addition to the non-refractory species measured by the standard AMS (sulfate, nitrate, ammonium, chloride, organics). In this study, the SP-AMS operated with tungsten and laser vaporization on 9-11 April 2010 after which the laser was turned off due to technical issues and the instrument operated only with the tungsten vaporizer.

The time resolution of the SP-AMS was set to 5 minutes. One third of the time the AMS measured in the particle timeof-flight mode (PToF, reporting chemically resolved size distributions) and the other two thirds in mass spectrum mode (MS, mass concentrations without particle size information). Mass spectra were measured with $\mathrm{V}$ and $\mathrm{W}$ modes but only V-mode data was analyzed further as with this vaporizer configuration the resolution of $\mathrm{W}$ mode was not better than that of $\mathrm{V}$ mode but the sensitivity of $\mathrm{W}$ mode was lower.

SP-AMS data was analyzed using a standard AMS data analysis software (SQUIRREL v1.49 and PIKA v1.08B) within Igor Pro 6 (Wavemetrics, Lake Oswego, OR). High resolution (HR) data was used for mass spectral analysis but for the size distributions only unit mass resolution (UMR) data was available. Black carbon was calculated following Onasch et al. (2012). All the SP-AMS species were calculated with a collection efficiency (CE) of 1 . The estimation
Table 1. Ambient temperature, relative humidity and the concentrations of gases during the field measurements at SMEAR III (SD: standard deviation, ppb: parts per billion).

\begin{tabular}{ll}
\hline & Measurement average \pm SD \\
\hline Ambient temperature & $5.5 \pm 2.3^{\circ} \mathrm{C}$ \\
Ambient relative humidity & $74 \pm 10 \%$ \\
$\mathrm{O}_{3}$ & $28.6 \pm 7.0 \mathrm{ppb}$ \\
$\mathrm{NO}$ & $2.69 \pm 3.6 \mathrm{ppb}$ \\
$\mathrm{NO}_{2}$ & $14.2 \pm 8.8 \mathrm{ppb}$ \\
$\mathrm{SO}_{2}$ & $0.81 \pm 0.6 \mathrm{ppb}$ \\
$\mathrm{CO}$ & $276 \pm 38 \mathrm{ppb}$ \\
\hline
\end{tabular}

of CE is more complex for the SP-AMS than for the HRToF-AMS as there are two vaporizers that have different factors affecting the CE (Onasch et al., 2012). As the focus of this study was in the efficiency of the m-VACES, not in the exact mass concentrations, $\mathrm{CE}=1$ was used for all the SPAMS species regardless of the vaporizer configuration or the use of the m-VACES. This could affect the results somewhat, especially for the laser vaporizer if particle size or shape changes through the concentrator, as the lens focusing depends on both size and shape (Huffman et al., 2005), or for the tungsten vaporizer if particle phase alters in the m-VACES (Matthew et al., 2008).

Positive matrix factorization (PMF, Paatero and Tapper, 1994; Lanz et al., 2007; Ulbrich et al., 2009) was conducted on the mass spectra of ambient and concentrated organic aerosol (OA) separately. Only the data without the laser (1114 April 2010) was selected for the PMF analysis in order to avoid the vaporization technique from influencing the solution. Before conducting the PMF analysis the data was averaged to 30 minutes giving only one data point for each ambient/concentrated period. The averaging was performed in order to ensure that the variation in the concentrating process did not affect the results of PMF. The APES (Analytic Procedure for Elemental Separation; Aiken et al., 2007, 2008) was used for the elemental analysis of the SP-AMS data.

\subsubsection{Other measurements}

The SMPS system used at SMEAR III was similar to that used in the laboratory tests, with the SPMS measuring particles from 15 to $420 \mathrm{~nm}$ (mobility diameter) with a time resolution of 3 minutes. Particle mass-size distribution was calculated with the SMPS software by using the density of $1.48 \mathrm{~g} \mathrm{~cm}^{-3}$ obtained earlier for particles measured in Helsinki (Saarnio et al., 2010).

Data from gaseous species was recorded by monitors at SMEAR III. Ozone $\left(\mathrm{O}_{3}\right)$ was measured with an API 400 analyzer (Teledyne Instruments, Advanced Pollution Instrumentation, USA), sulfur dioxide $\left(\mathrm{SO}_{2}\right)$ with a TEI 43iTL (Thermo Fisher Scientific, USA) analyzer, and nitrogen oxides $\left(\mathrm{NO}_{\mathrm{x}}\right)$ with an API 200AU (Teledyne Instruments) 


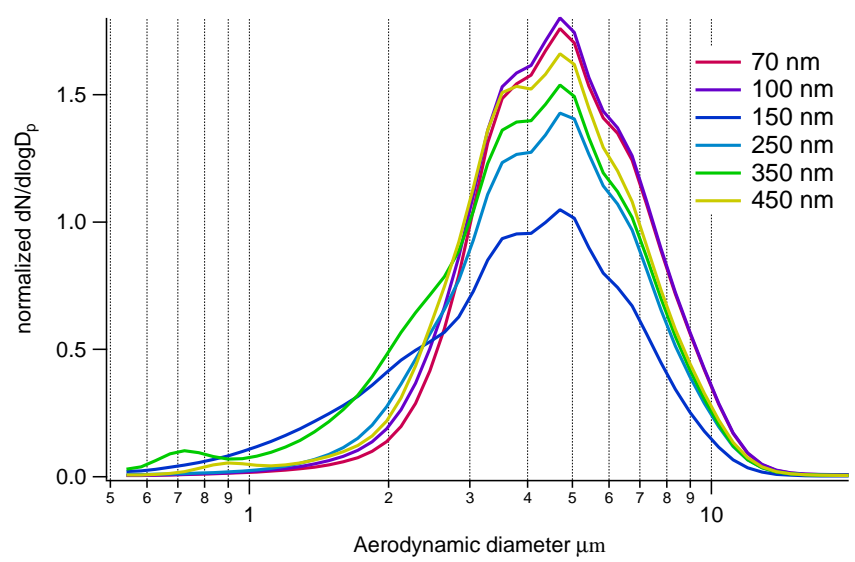

Figure 1. Droplet size for monodisperse AS particles. Concentrations ( $y$ axis) were normalized by dividing the concentrations by the total particle concentrations upstream of the m-VACES (13$35 \mathrm{~A} \mathrm{~cm}^{-3}$ ).

analyzer. For the measurement of $\mathrm{NO}_{\mathrm{x}}$ the instrument converts nitrogen dioxide $\left(\mathrm{NO}_{2}\right)$ to nitrogen monoxide $(\mathrm{NO})$ with a molybdenum converter. Carbon monoxide (CO) was measured with a Horiba APMA 370 (Horiba Europe $\mathrm{GmbH}$, Germany). Weather parameters were measured with a Vaisala weather station. Average meteorological parameters and gas concentrations during the m-VACES measurements at SMEAR III are shown in Table 1.

\section{Results and discussion}

\subsection{Performance of $\mathrm{m}$-VACES for monodisperse particles in the laboratory}

\subsubsection{Droplet size}

Droplet sizes downstream of the m-VACES were tested by using monodisperse ammonium sulfate aerosol. AS particles were generated with the atomizer and the size was selected with the DMA of the SMPS. Monodisperse AS particles were directed to the saturator, chiller and VI, and they were measured with the APS without drying. Six different particle sizes were selected from the DMA: 70, 100, 150, 250, 350 and $450 \mathrm{~nm}$ (mobility diameter).

The original size of ammonium sulfate particle did not affect the obtained droplet size distribution (Fig. 1). For each tested size, the maximum of the droplet size was at $4.7 \mu \mathrm{m}$, however, the shape of the size distributions varied slightly for different AS sizes. For 150 and $350 \mathrm{~nm}$ particles, there were more droplets below $2.5 \mu \mathrm{m}$ than for the other sizes, and there was also a separate, smaller mode for $350 \mathrm{~nm}$ AS particles at $0.7 \mu \mathrm{m}$ and for $450 \mathrm{~nm}$ particles at $0.9 \mu \mathrm{m}$. Differences in the size distributions were caused by varying temperature in the saturator. The heating in the saturator was maintained as constant as possible, but there was a small

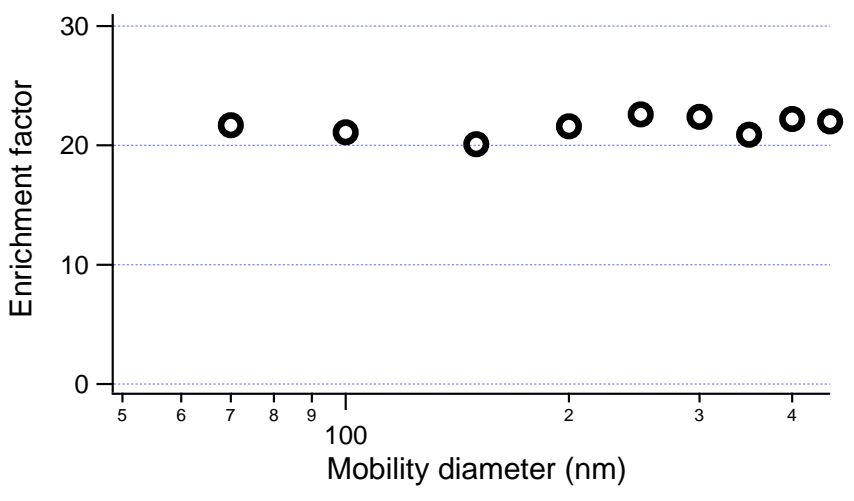

Figure 2. Enrichment factor for monodisperse AS particles measured with the CPC. Theoretical enrichment factor was 30 .

fluctuation in temperature $\left(\sim 2^{\circ} \mathrm{C}\right)$ in the course of droplet size measurements, which was directly related to the fraction of droplets below $2.5 \mu \mathrm{m}$. The dependence of droplet size on saturator temperature was described earlier by Geller et al. (2005). The exact size distribution of droplets does not affect the performance of the m-VACES as long as the droplets are above $2.5 \mu \mathrm{m}$ in aerodynamic size, which is the cutoff of the virtual impactor. In this study the percentage of droplets below $2.5 \mu \mathrm{m}$ varied from $6.2 \%(70 \mathrm{~nm})$ to $24 \%(150 \mathrm{~nm})$, which can cause a somewhat lower enrichment ratio in the $\mathrm{m}$ VACES than theoretically calculated. More accurate and automated temperature control of the saturator is recommended for future studies to reduce such losses.

\subsubsection{Enrichment ratio}

The enrichment of monodisperse particles in the m-VACES was measured by adding a dryer to the measurement setup and replacing the APS by the W-CPC. The size of AS particles did not have an impact on the enrichment factor in the $\mathrm{m}$-VACES. EF was calculated as the ratio of aerosol number/mass concentration after the m-VACES to that without the m-VACES. A consistent enrichment factor of 20-23 was obtained for 70-450 nm monodisperse AS particles (Fig. 2), which was lower than the theoretical EF of 30 likely due to particle losses in saturator, condenser, droplet separation and diffusion dryer. Such losses do not appear to depend on the size of the original particles, and thus losses of droplets smaller than the impactor cutpoint of $2.5 \mu \mathrm{m}$ appear a likely cause.

\subsubsection{Particle size}

The influence of m-VACES on particle size was studied by substituting the W-CPC with the SMPS in order to measure the size distributions upstream and downstream of the $\mathrm{m}$ VACES. Five sizes of monodisperse AS particles were measured with the SMPS. For $300 \mathrm{~nm}$ particles the size distribution was preserved after the m-VACES but for the smaller 
Table 2. Concentrations and EFs (average \pm SD) of particle number and mass, SP-AMS species and total mass from the SP-AMS measured for ambient and concentrated aerosols. SP-AMS species are calculated with the collection efficiency of 1 .

\begin{tabular}{|c|c|c|c|}
\hline Species & $\begin{array}{l}\text { Ambient } \\
\text { concentration }\end{array}$ & $\begin{array}{l}\text { Concentrated } \\
\text { concentration }\end{array}$ & $\begin{array}{l}\text { Enrichment } \\
\text { factor }\end{array}$ \\
\hline Particle number $\left(\# \mathrm{~cm}^{-3}\right)$ (SMPS) & $4.58 \pm 2.1 \times 10^{3}$ & $1.25 \pm 0.48 \times 10^{5}$ & $27.9 \pm 4.9$ \\
\hline Particle mass ${ }^{\mathrm{a}}\left(\mu \mathrm{g} \mathrm{m}^{-3}\right)$ (SMPS) & $8.00 \pm 6.0$ & $1.80 \pm 0.96 \times 10^{2}$ & $23.0 \pm 2.3$ \\
\hline Organics $\left(\mu \mathrm{g} \mathrm{m}^{-3}\right)$ & $2.10 \pm 1.0$ & $58.1 \pm 28$ & $27.1 \pm 3.8$ \\
\hline Nitrate $\left(\mu \mathrm{g} \mathrm{m}^{-3}\right)$ & $0.259 \pm 0.23$ & $6.76 \pm 6.4$ & $24.3 \pm 3.5$ \\
\hline Sulfate $\left(\mu \mathrm{g} \mathrm{m}^{-3}\right)$ & $0.753 \pm 0.31$ & $19.1 \pm 8.6$ & $24.6 \pm 3.8$ \\
\hline Ammonium $\left(\mu \mathrm{g} \mathrm{m}^{-3}\right)$ & $0.284 \pm 0.16$ & $9.90 \pm 4.6$ & $39.5 \pm 12$ \\
\hline $\mathrm{r}-\mathrm{BC} \mathrm{C}^{\mathrm{b}}\left(\mu \mathrm{g} \mathrm{m}^{-3}\right)$ & $0.203 \pm 0.13$ & $6.07 \pm 3.9$ & $27.6 \pm 4.2$ \\
\hline Total mass ${ }^{b}\left(\mu \mathrm{g} \mathrm{m}^{-3}\right)$ (SP-AMS) & $3.81 \pm 1.6$ & $1.07 \pm 0.45 \times 10^{2}$ & $27.6 \pm 4.4$ \\
\hline
\end{tabular}

a Density of $1.48 \mathrm{~g} \mathrm{~cm}^{-3}, \mathrm{~b}$ only with the laser on.

sizes, especially for 50 and $70 \mathrm{~nm}$, a shift to larger sizes was observed (Fig. 3a; Table S1 in the Supplement). The shift of the peak maximum varied between $4 \mathrm{~nm}$ for $100 \mathrm{~nm}$ particles and $10 \mathrm{~nm}$ for $50 \mathrm{~nm}$ AS particles. Particle concentration did not affect the shift, which rules out particle coagulation as a potential cause of the shift. However, the size shift increased when the temperature in the saturator was higher. Dry AS particles are approximately but not perfectly spherical (Huffman et al., 2005), in order to completely rule out an effect of particle shape on the DMA measurements and on the shift, AS particles were replaced by DOS particles that are liquid and spherical. For $50 \mathrm{~nm}$ DOS particles the shift was slightly smaller than for AS particles but for all other sizes the shift was similar (Fig. 3b; Table S1 in the Supplement), which confirmed that the shift was not due to a change in particle shape through the concentrator, and that it did not depend on particle composition.

The size shift for small particle sizes has been observed earlier also for other concentrator designs (Su et al., 2006; Rastogi et al., 2012). Rastogi et al. (2012) suggested various explanations for the shift: (1) inefficient growth of very small particles with subsequent loss to major airstream within virtual impactors, (2) inefficient water removal during the drying process and/or (3) condensation of organic compounds on the droplets that did not volatilize in the drying process causing irreversible growth. In this study, the third explanation seems to be the most plausible reason for the size shift and most likely caused by the gas-particle partitioning of water-soluble semivolatile organic compounds (SVOCs). SVOCs can be present in ambient air but it is also possible that the material condensing on the particles originates from the cellulose sponge material used in the saturator as the increasing temperature in the saturator releases more material from the sponges. For hypothesis (1), particle number concentration was measured also in the major flow in the laboratory (not shown), but there were no particle losses that could explain the shift, consistent with the lack of dependence of the concentration factor on particle size discussed earlier. For hypothesis (2), remnant water, the drying process was tested by using two diffusion dryers in row but the size shift did not change (not shown). In ambient measurements (reported in Sect. 3.2) it will be shown that the additional mass is likely to be made of organics, mostly hydrocarbons.

\subsection{Performance of $\mathrm{m}$-VACES in ambient atmosphere}

m-VACES was used to concentrate ambient aerosol in Helsinki, Finland in April 2010. The performance of the mVACES in the field was assessed by investigating the effect of concentrating process on particle number and mass measured with the SMPS, and chemical species determined by the SP-AMS.

\subsubsection{Particle mass and number concentrations}

In general, the enrichment factor was smaller for particle mass than for particle number (Table 2). That can be explained by high EF for small particles, seen when EF is presented as a function of particle size (Fig. 4a). For $20 \mathrm{~nm}$ particles EF was around half of the theoretical value of 30 , after which it started to increase towards the maximum at 30 $40 \mathrm{~nm}$. The maximum value of $\mathrm{EF}$ was $\sim 40$, which is larger than the theoretically possible value of $\sim 30$ likely due to the size shift of smaller particles found in the laboratory tests. After the peak value EF began to decrease again and had a plateau for larger sizes $(E F \sim 22)$. Inefficient enrichment of particles $<20 \mathrm{~nm}$ was similarly reported in Ning et al. (2006) for the m-VACES.

Average number and mass-size distributions for concentrated and ambient aerosol are presented in Fig. $4 \mathrm{~b}$ and $\mathrm{c}$ and the time evolution of size distributions in Fig. S1 in the Supplement. Concentrated aerosols had fewer particles below $\sim 25 \mathrm{~nm}$ (mobility diameter) than ambient aerosols but there were more particles from 25 to $100 \mathrm{~nm}$ in concentrated than in ambient number-size distribution (Fig. 4b). During some periods, particles may be present below the cutpoint of the SMPS, as the size distributions are not going to zero 

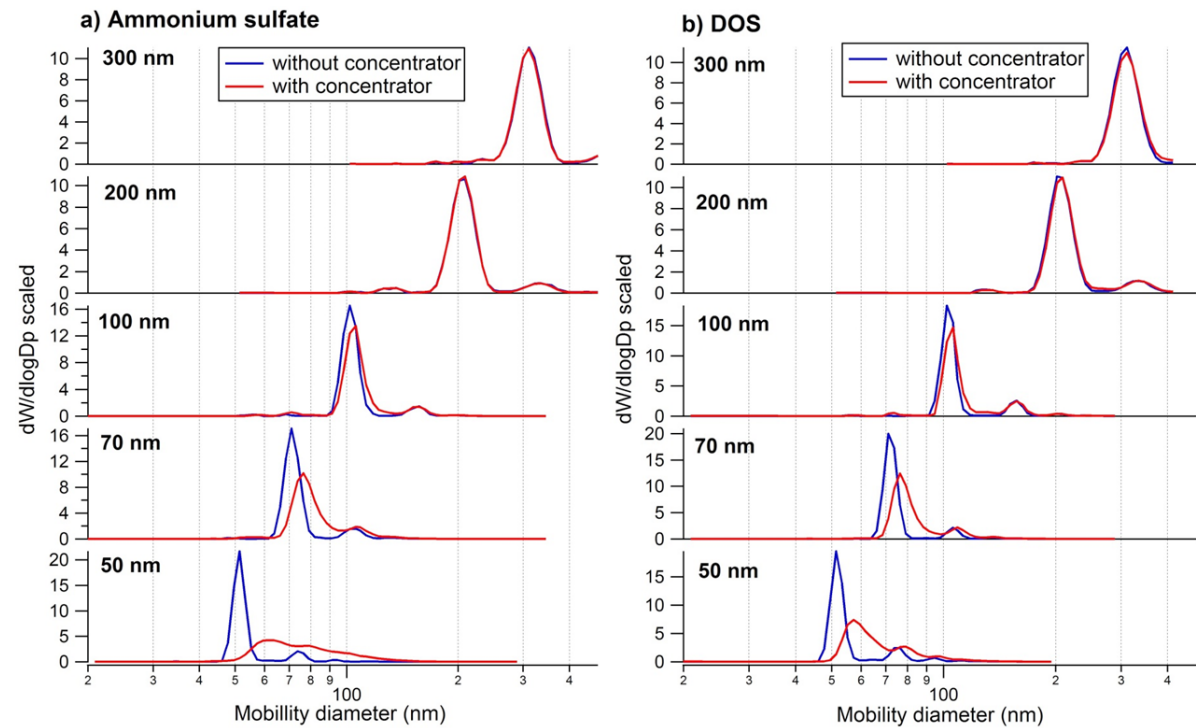

Figure 3. Number-size distributions for monodisperse AS (a) and DOS (b). Results have been scaled according to the total number concentrations.
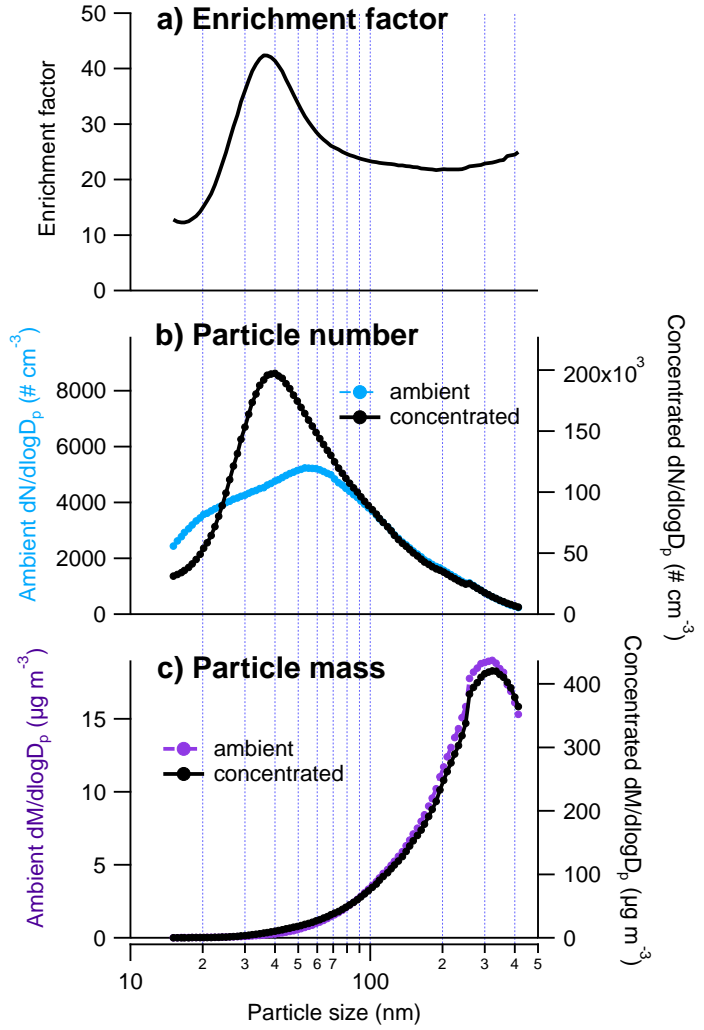

Figure 4. Size distributions for enrichment factor (a), ambient and concentrated particle number (b) and mass (c) measured with the SMPS. Particle mass was calculated by using the density of $1.48 \mathrm{~g} \mathrm{~cm}^{-3}$. at small sizes. Those particles may also be growing into the SMPS size range in the concentrator resulting in an apparently larger enrichment at the smallest detectable sizes. For the mass-size distributions, there was no significant difference between the ambient and concentrated distributions (Fig. 4c). That is because the majority of mass is in the size range where $\mathrm{EF}$ was quite constant and close to the average (or ideal) value. EF for particle number concentrations varied in time more than those for mass (Fig. 5a). This may be due to the changes in the shape of number-size distribution and intermittent presence of new particle formation, and the strong dependence of EF on particle size. However, EF neither for number nor mass correlated with ambient temperature or humidity, ambient mass / number concentration or any gas-phase species measured $\left(\mathrm{O}_{3}, \mathrm{NO}, \mathrm{NO}_{2}, \mathrm{SO}_{2}\right.$ or $\left.\mathrm{CO}\right)$.

\subsubsection{Particle chemical composition}

The average chemical composition of particles was very similar for ambient and concentrated aerosols (Fig. 6). The fractional contribution of organics and nitrate was equal for ambient and concentrated aerosols, whereas for sulfate it was slightly smaller, and for r-BC it was slightly larger for concentrated than for ambient particles. Overall these differences were quite small. The largest difference was observed for ammonium. Ammonium had a 50\% larger contribution in concentrated than in ambient aerosols. The behavior of chemical species in the m-VACES is discussed in more detail in the next sections. 
a)

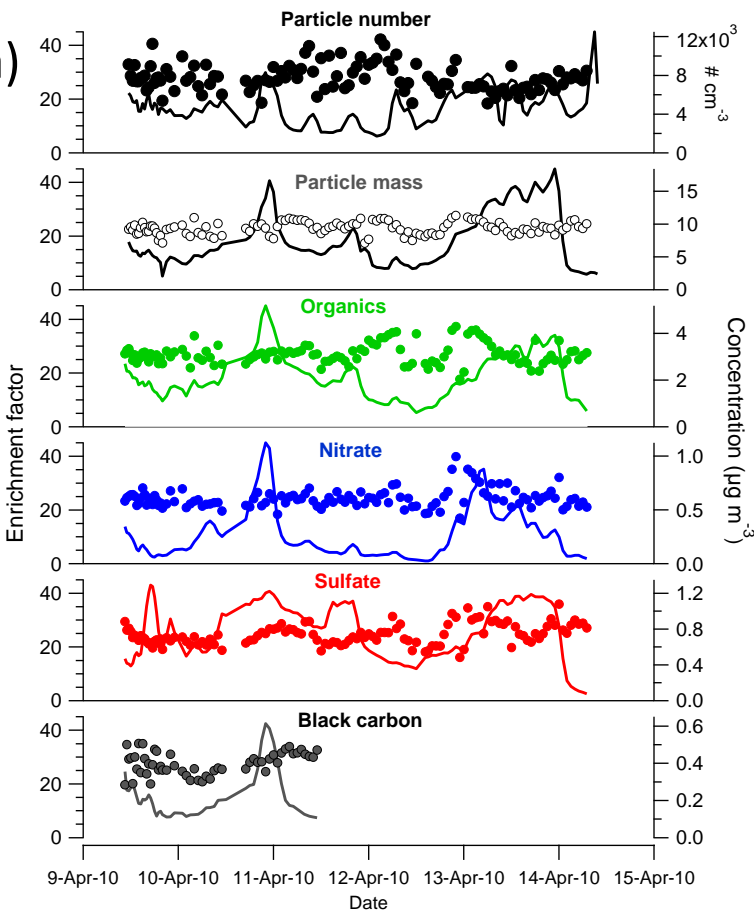

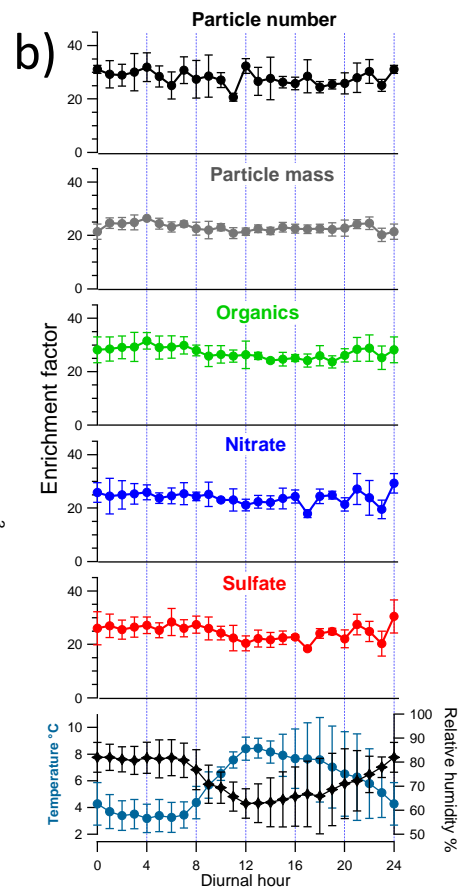

Figure 5. Time series for EFs (dots) and ambient concentrations (lines) (a) and diurnal trends for EFs, ambient temperature and relative humidity (b). Particle number and mass were measured with the SMPS and organics, nitrate and sulfate and r-BC with the SP-AMS. Particle mass was calculated by using the density of $1.48 \mathrm{~g} \mathrm{~cm}^{-3}$. Diurnal trend for EF of $\mathrm{r}-\mathrm{BC}$ is not shown as it was calculated only when the laser was on (2 days). Ammonium is shown separately in Fig. 8.
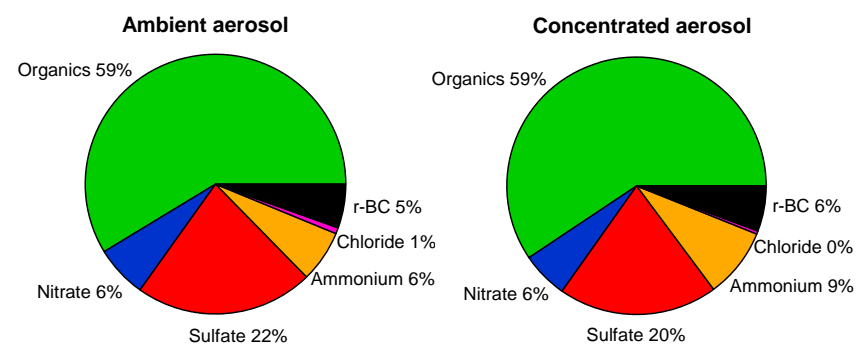

Figure 6. Average chemical composition of ambient and concentrated particles measured with the SP-AMS laser on.

\subsubsection{Inorganic species}

Sulfate and nitrate had similar enrichment factors averaged over the whole measurement period (Table 2; Fig. 5). EFs for sulfate and nitrate were slightly larger than that for particle mass but smaller than for particle number. Similar to particle number and mass, ambient relative humidity, temperature, measured gases, or aerosol species ambient concentrations did not correlate with EFs for nitrate or sulfate. Regarding the diurnal patterns (Fig. 5b), there was a minor diurnal trend for sulfate with slightly smaller EF in the afternoon than in the night and morning, however, there were only 5 days of data and thus the uncertainty in diurnal trends is large.
The size distributions of sulfate and nitrate changed slightly during the concentrating process in the m-VACES (Fig. 7a). On average, nitrate peaked at a smaller size than sulfate, the accumulation mode shifting from $430 \mathrm{~nm}$ in ambient aerosol to $480 \mathrm{~nm}$ in concentrated aerosol whereas for sulfate the shift was from 480 to $540 \mathrm{~nm}$. Size-dependent EFs for nitrate and sulfate both had a maximum at $530 \mathrm{~nm}$ (Fig. 7b).

Enrichment of ammonium deviated clearly from that of sulfate and nitrate. Average EF for ammonium was clearly larger $(E F \sim 40)$ than for the other species (Table 2) or the theoretical value of 30 . High enrichment of ammonium in the $\mathrm{m}$-VACES was associated with periods of high acidity of ambient aerosols. The time series for the acidity of ambient particles, expressed here as the ratio of cationic to anionic charge measured by the SP-AMS, is shown in Fig. 8a. It can be seen from the time series that the particles were relatively acidic (small ratio of SP-AMS cationic to anionic charge) from the beginning of the measurement period until the midday of 10 April and from the midnight to evening on 12 April 2010. At the same time, with the increasing acidity, EF for ammonium increased. In general, there was a clear correlation between EF for ammonium and the ratio of SP-AMS cationic to anionic charge (Fig. 8b). This finding suggested that gaseous ammonia neutralized acidic ambient aerosol, as evidenced by the neutralized aerosol after the m-VACES (Fig. 8a; Table 3). 
a)

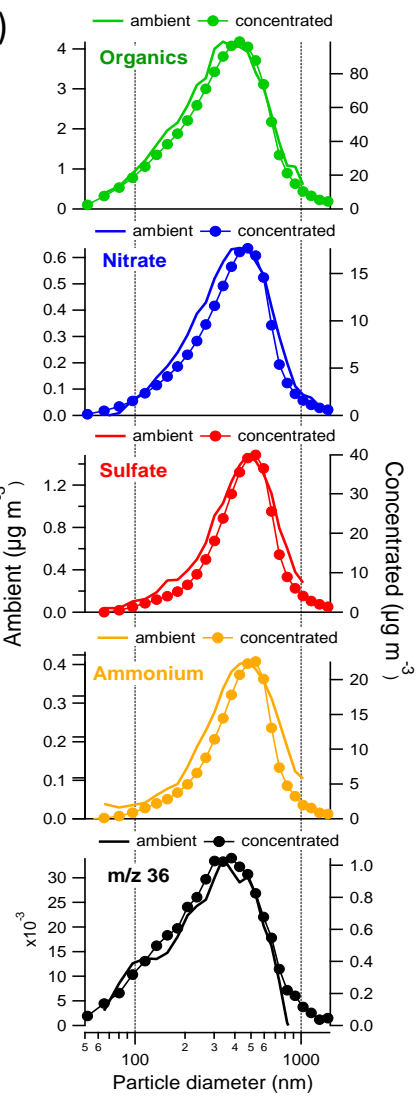

b)

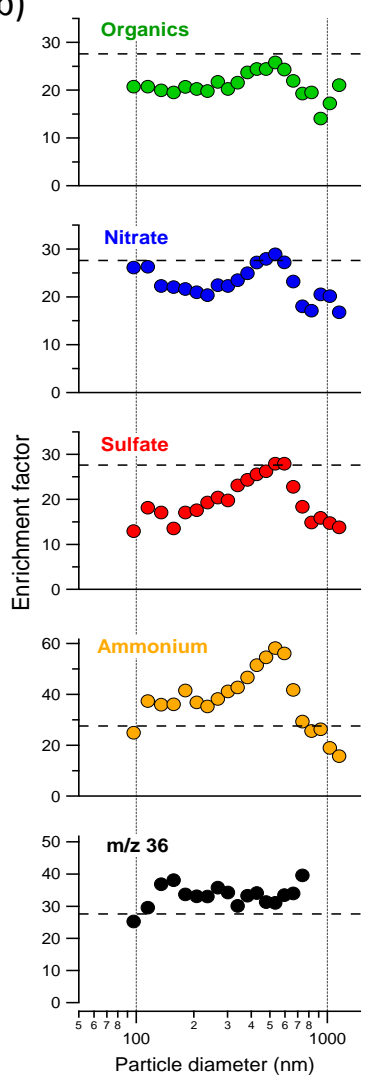

Figure 7. Average mass-size distributions for organics, nitrate, sulfate, ammonium and $m / z, 36$ (surrogate for r-BC) for ambient and concentrated aerosol (a) and the corresponding EFs (b). $m / z 36$ was measured only with the laser on. Clear outliers were excluded from (b) and ammonium and $m / z, 36$ were smoothed by 1 point due to low a signal-to-noise ratio for ambient size distributions. Dashed lines in (b) represent the average EF for the SP-AMS (26.7).

However, it is still unclear why the aerosol was not neutralized by the ammonia already present in ambient air. It is possible that ammonia accumulated previously in the sponges of the saturator of the m-VACES and was released when acidic aerosol was present. This phenomenon has been observed for ammonium emissions from soil: acidic aerosol induced emission rates of ammonia from the land surface (Ellis et al., 2011). Gaseous ammonia could also have been dissolved in the recirculating water in the m-VACES, as it is a highly soluble gas, and released in the saturator as the temperature increased, however, that should be verified by additional laboratory and field tests. Jung et al. (2010) have tested the enrichment of gaseous ammonia in the VACES. They observed a slight enrichment of ammonia in their experiments but concluded that the saturator water bath was not a major sink for gaseous ammonia.

The adsorption of gaseous ammonia was not seen in the size distributions of ammonium if the particles were not acidic. The size distributions during the enhanced

Table 3. Ratio of SP-AMS cationic to anionic charge and elemental ratios for organics. Ambient and concentrated aerosol (average \pm SD).

\begin{tabular}{lll}
\hline Ratio & Ambient & Concentrated \\
\hline Cationic to anionic charge & $0.703 \pm 0.16$ & $1.053 \pm 0.053$ \\
OM: OC & $1.61 \pm 0.08$ & $1.61 \pm 0.07$ \\
O:C & $0.36 \pm 0.06$ & $0.35 \pm 0.05$ \\
H:C & $1.42 \pm 0.11$ & $1.61 \pm 0.06$ \\
$\mathrm{~N}: \mathrm{C}$ & $8.24 \pm 24 \times 10^{-3}$ & $15.1 \pm 4.6 \times 10^{-3}$ \\
\hline
\end{tabular}

ammonium period (12 April) and the following day, when the ambient aerosol was almost neutral (13 April, from 06:00 LT (local time) to midnight), were alike (Fig. S2 in the Supplement), likely as the condensation of ammonia was driven by the size distribution of the anions. On average, ammonium had a somewhat wider accumulation mode for concentrated than for ambient aerosol, with a size-dependent EF peaking at $530 \mathrm{~nm}$ (Fig. 7) similar to sulfate and nitrate. A slight enrichment for ammonium has been noticed earlier in the laboratory and ambient tests in the VACES (Jung et al., 2010).

Aerosol acidity has been reported to affect the enrichment of nitrate in the VACES in Pittsburg (Khlystov et al., 2005). The reason for the formation of the extra nitrate in the concentrator in that study was attributed to the transfer of nitric acid from the gas to the aerosol phase. The nitrate artifact was observed on days when the ammonium was in deficit to fully neutralize the measured sulfate and nitrate; however, on a clean day, when ambient aerosol was neutralized, no discernible artifact was observed. Extra nitrate was mostly found at small sizes forming an additional mode in the size range of $100-200 \mathrm{~nm}$.

The m-VACES together with the SP-AMS enabled the investigation of trace elements. Five trace elements were detected in ambient air without the m-VACES; aluminum, vanadium, iron, zinc and rubidium. The use of the m-VACES also allowed detecting additional trace elements, strontium, zirconium and cadmium that could not be observed without the concentrator. As the detection of trace elements was only qualitative it is discussed in more detail in the Supplement.

\subsubsection{OA and r-BC}

Enrichment factors were slightly larger for $\mathrm{OA}$ and r-BC than for nitrate and sulfate (Table 2). Similar to sulfate, also for OA there was a minor diurnal pattern with smaller $\mathrm{EF}$ in the afternoon than in the night and morning (Fig. 5b). Regarding the size distributions, the location of the accumulation mode shifted more for organics than for inorganics in the m-VACES (Fig. 7). This was probably due to the fact that the maximum of organics was located at smaller sizes than that of inorganics. OA peaks at $340 \mathrm{~nm}$ in ambient aerosol, whereas the peak of the mode was at $430 \mathrm{~nm}$ in concentrated aerosol. The size-dependent $\mathrm{EF}$ for $\mathrm{OA}$ was quite 

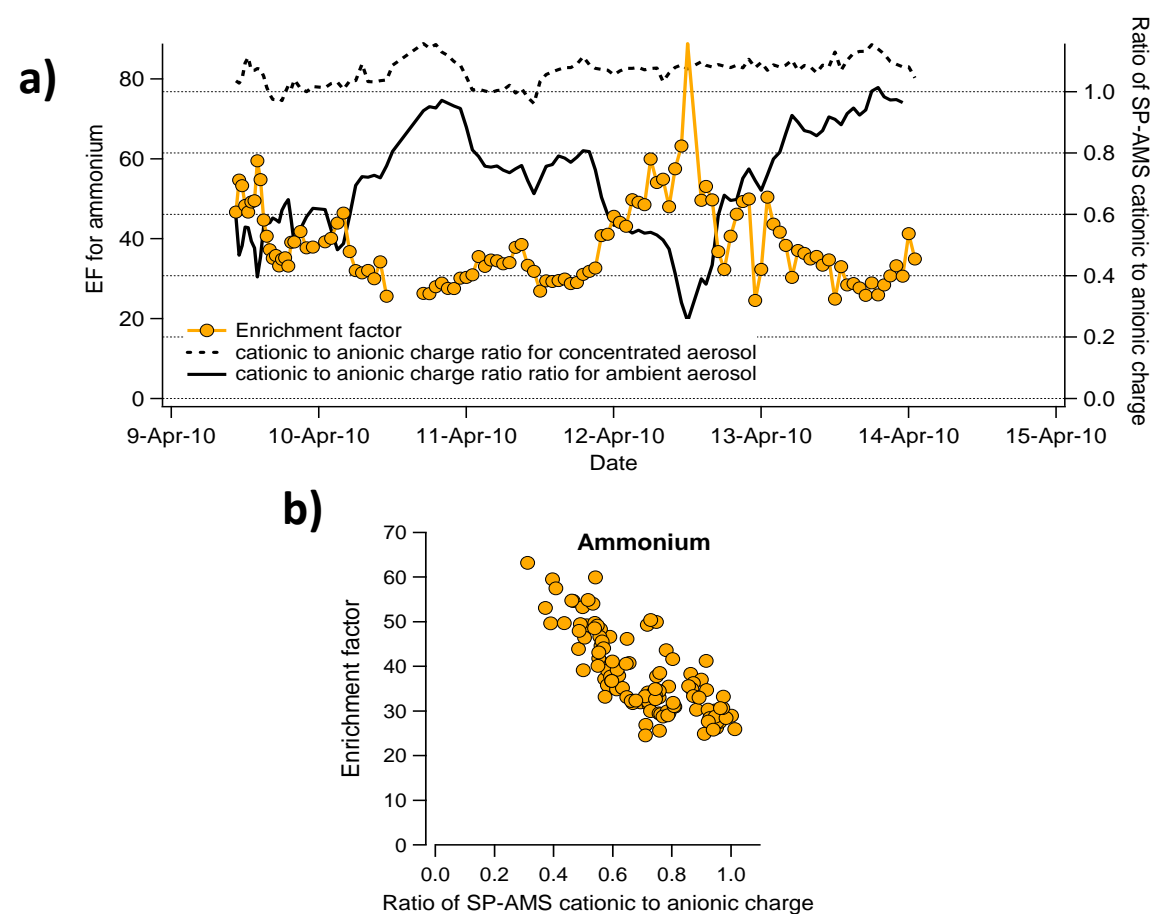

Figure 8. The ratio of SP-AMS cationic to anionic charge for ambient and concentrated aerosol and the enrichment ratio for ammonium (a), and the correlation between EF and the ratio of SP-AMS cationic to anionic charge for ammonium (b).

stable until $350 \mathrm{~nm}$ after which it increased slightly reaching a maximum at $530 \mathrm{~nm}$ (Fig. 7b). The smaller accumulation mode peak for organics vs. inorganics was likely due to local sources for OA, such as traffic and residential heating with wood, whereas sulfate and nitrate originated mostly from long-range transport (Timonen et al., 2008).

For $\mathrm{r}-\mathrm{BC}$, the size-dependent EF could not be calculated but, similar to Massoli et al. (2012), $m / z 36$ was used as a surrogate for $\mathrm{r}-\mathrm{BC}$ as it was the strongest carbon cluster signal. For $m / z 36$ the size distribution for ambient and concentrated aerosol agreed well (Fig. 7). Similar to other species, ambient relative humidity, temperature, gases, or species ambient concentrations did not affect EFs for organics or r-BC.

The properties of organic aerosol appeared to change only slightly during the concentration process. Mass fragments of concentrated $\mathrm{OA}$ and $\mathrm{r}-\mathrm{BC}$ were plotted against those of ambient $\mathrm{OA}$ and $\mathrm{r}-\mathrm{BC}$ classified according to their elemental composition (Fig. S3). For oxidized organic compounds $\left(\mathrm{C}_{\mathrm{x}} \mathrm{H}_{\mathrm{y}} \mathrm{O}^{+}\right.$and $\left.\mathrm{C}_{\mathrm{x}} \mathrm{H}_{\mathrm{y}} \mathrm{O}_{\mathrm{z}}^{+}, \mathrm{z}>1\right)$ most of the ions had similar relative concentrations in ambient and concentrated $\mathrm{OA}$; however, the $\mathrm{CO}_{2}^{+}$fragment was $25 \%$ lower for concentrated than for ambient OA. Also the relative concentrations of ambient and concentrated hydrocarbon-like ions $\left(\mathrm{C}_{\mathrm{x}} \mathrm{H}_{\mathrm{y}}^{+}\right)$correlated strongly but $\mathrm{C}_{3} \mathrm{H}_{7}^{+}(\mathrm{m} / z, 43)$ had double the relative concentration in concentrated OA compared to that in ambient OA. This could be due to the fact that the concentrator made the small particles that are normally outside of the AMS transmission curves grow so that they were detected much more efficiently after the concentrator or due to the organic impurities in the sponges (as already discussed in Sect. 3.1.3.).

Hydrocarbon-like compounds can also originate from more efficient partitioning of SVOCs into the particle phase in the m-VACES. The artifacts of SVOCs in the VACES have been investigated in Wang et al. (2013). They showed a positive total organic carbon (TOC) sampling artifact of 15-20\% for a typical ambient TOC concentration of $10 \mu \mathrm{g} \mathrm{m} \mathrm{m}^{-3}$ over Los Angeles in the summer season. However, their experiments were conducted at high ambient temperature and photochemical activity so lower levels of SVOC artifacts can be expected if the sampling is conducted in a colder season, as in this paper.

Some mass fragments of OA also contained nitrogen atoms. Of nitrogen-containing fragments the highest signals were observed for $\mathrm{CH}_{4} \mathrm{~N}^{+}(\mathrm{m} / z$ 30.034), followed by $\mathrm{C}_{2} \mathrm{H}_{4} \mathrm{~N}^{+}\left(m / z\right.$ 42.034) and $\mathrm{C}_{3} \mathrm{H}_{6} \mathrm{~N}^{+}(m / z$ 56.050). For the $\mathrm{C}_{\mathrm{x}} \mathrm{H}_{y} \mathrm{~N}^{+}$ions the relative concentrations were significantly and consistently higher in concentrated than in ambient aerosol. For $\mathrm{CH}_{4} \mathrm{~N}^{+}, \mathrm{C}_{2} \mathrm{H}_{4} \mathrm{~N}^{+}$and $\mathrm{C}_{3} \mathrm{H}_{6} \mathrm{~N}^{+}$the relative concentrations in the m-VACES were 2.0, 2.4 and 1.8 times those in ambient aerosol, respectively. This would suggest neutralization of acidic aerosols by amines (e.g., Smith et al., 2010), similar to the higher enhancement of ammonium observed above. The time series of $\mathrm{CH}_{4} \mathrm{~N}^{+}, \mathrm{C}_{2} \mathrm{H}_{4} \mathrm{~N}^{+}$ and $\mathrm{C}_{3} \mathrm{H}_{6} \mathrm{~N}^{+}$correlated with that of ammonium for the concentrated aerosol $\left(R^{2}=0.72,0.69\right.$ and 0.62 , respectively; 
a)

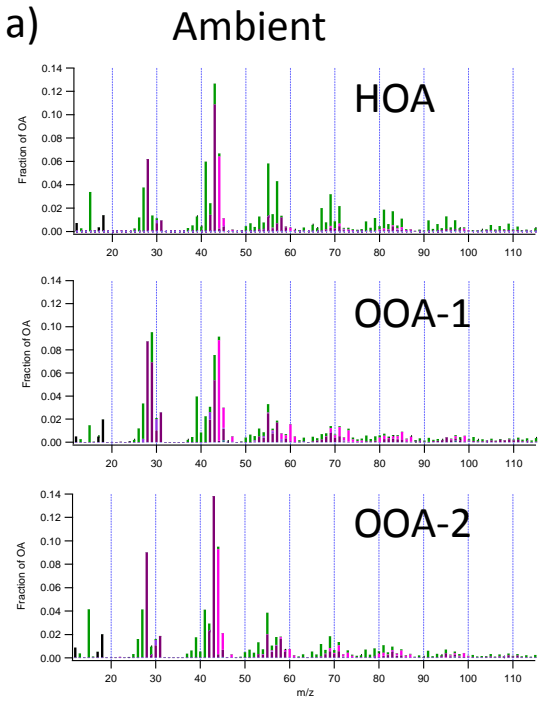

Concentrated
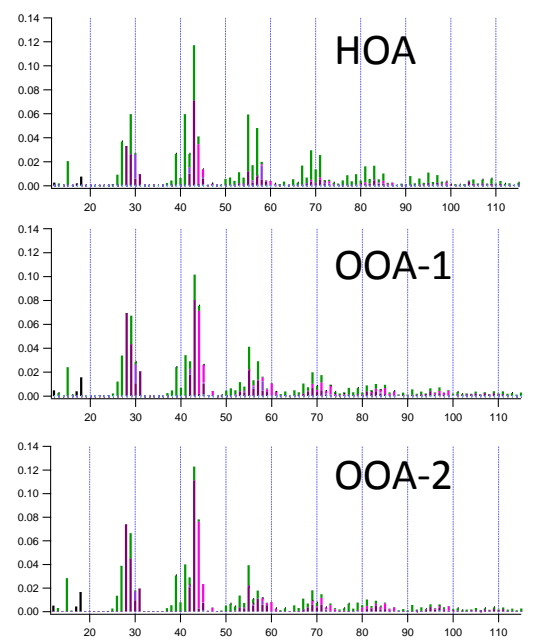

b)
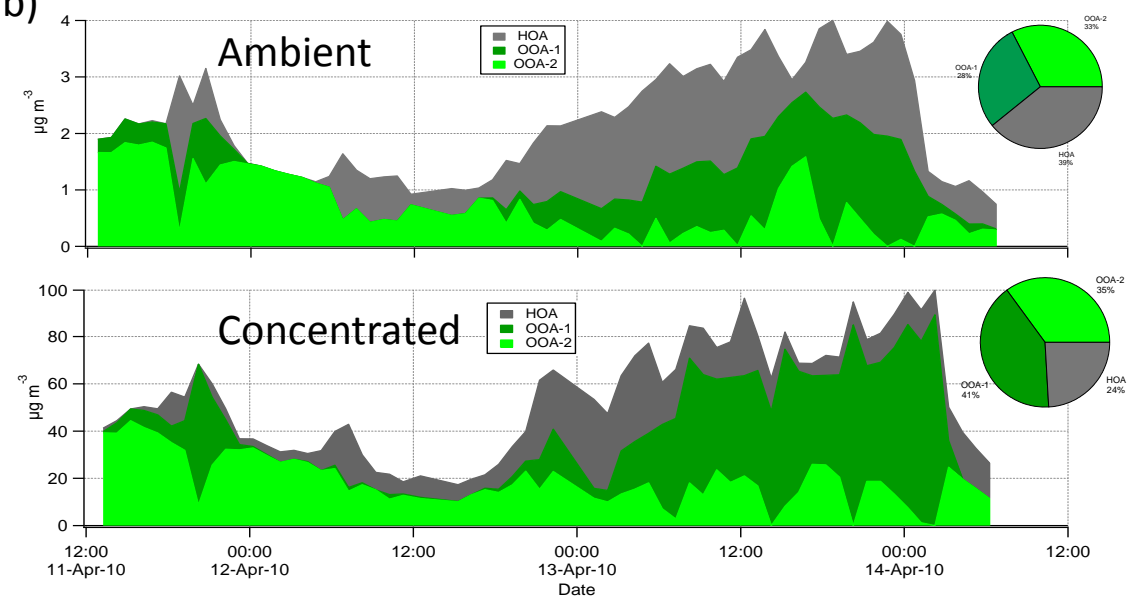

Figure 9. PMF factors for ambient and concentrated OA. Mass spectra (a), and time series and average contributions to OA (b).

Fig. S4 in the Supplement), however, there were no correlations for ambient aerosol or for EFs. Su et al. (2006) have investigated the concentration enrichment of amines with various particle concentrators. They found that the ion signals from amines were reduced after the HUCAPS, possibly due to volatilization losses during the thermal drying process, whereas amines increased in the fine particles $(100-300 \mathrm{~nm})$ in the VACES. The presence of more acidic aerosols in this study may have caused the different behavior observed here.

Average ratios of organic matter to organic carbon (OM : OC) and oxygen to carbon $(\mathrm{O}: \mathrm{C})$ were similar for ambient and concentrated OA (Table 3). Regarding diurnal trends, $\mathrm{OM}: \mathrm{OC}$ and $\mathrm{O}: \mathrm{C}$ were slightly larger in the afternoon and evening than in the night and morning (Fig. S5 in the Supplement). Higher OM:OC and O:C indicated more oxidized OA and the formation of secondary organic aerosol (SOA), however the amount of SOA formation was rather small due to the limited amount of solar radiation in
Finland in early April. The hydrogen to carbon ratio $(\mathrm{H}: \mathrm{C})$ was slightly larger for concentrated OA than for ambient $\mathrm{OA}$, which agrees with the higher relative concentration of $\mathrm{C}_{3} \mathrm{H}_{7}^{+}$mentioned earlier. The nitrogen to carbon ratio $(\mathrm{N}: \mathrm{C})$ for concentrated OA was almost twice of that for ambient $\mathrm{OA}$, consistent with the elevated nitrogen-containing ions discussed above.

\subsubsection{Source apportionment for $\mathrm{OA}$}

Positive matrix factorization was conducted on the mass spectra of OA measured with and without the m-VACES. For both ambient and concentrated data, three-factor solutions were selected for further investigation. Factors were identified as hydrocarbon-like OA (HOA) and two factors for oxygenated OAs (OOA; denoted here as OOA-1 and OOA-2). HOA had a characteristic hydrocarbon pattern in the mass spectrum whereas OOAs had a high signal for $\mathrm{CO}_{2}^{+}$(Fig. 9a). 


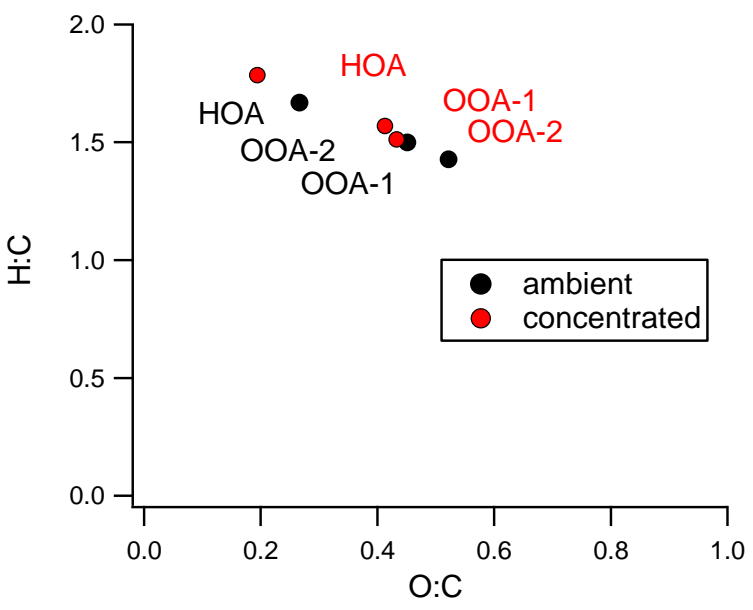

Figure 10. Location of the PMF factors at $\mathrm{O}: \mathrm{C}$ and $\mathrm{H}: \mathrm{C}$ spaces. Black circles are for ambient and red circles for concentrated OA.

OOA-1 and OO-2 had quite similar mass spectra; however, there were some minor differences between OOAs, e.g., $\mathrm{C}_{2} \mathrm{H}_{3} \mathrm{O}^{+}(\mathrm{m} / z$ 43.018) had a much lower fraction in OOA1 than in OOA-2 and the biomass burning marker $\mathrm{C}_{2} \mathrm{H}_{4} \mathrm{O}_{2}^{+}$ $(\mathrm{m} / \mathrm{z}$ 60.021; Lee et al., 2010) had a higher fraction in OOA1 than in OOA-2 (Fig. 9a). OOA-1 also correlated with sulfate, nitrate and gaseous $\mathrm{CO}$ whereas OOA-2 did not correlate with any of the chemical species measured. We hypothesize that OOA-1 was mostly a mixture of emissions from eastern/central Europe transported to Finland whereas OOA2 originated mainly from local sources.

The concentrating process changed the PMF factors to some extent. The time series and mass spectra of ambient and concentrated OOA- 1 were well correlated $\left(R^{2}=0.90\right.$ and 0.89, respectively, Fig. S6 in the Supplement); however, the average fraction of OOA-1 was much larger in concentrated than in ambient OA (Fig. 9b). In case of OOA-2, the mass spectra of ambient and concentrated OA correlated well $\left(R^{2}=0.91\right)$ with only $\mathrm{CHO}^{+}$deviating from the pattern, but the time series of OOA-2 had some dissimilarities in ambient and concentrated data sets $\left(R^{2}=0.56\right)$. The average fraction of OOA-2 in OA was almost equal for ambient and concentrated data. In general, both OOA-1 and OOA-2 were slightly less oxidized after the $\mathrm{m}$-VACES and their $\mathrm{O}: \mathrm{C}$ ratios moved closer to each other (Fig. 10). HOA had the largest difference between the ambient and concentrated data. The time series of ambient and concentrated HOA had a low correlation $\left(R^{2}=0.39\right)$ and regarding the mass spectra, HOA had much higher fraction of $\mathrm{C}_{\mathrm{x}} \mathrm{H}_{\mathrm{y}}^{+}$ions, e.g., $\mathrm{C}_{3} \mathrm{H}_{3}^{+}, \mathrm{C}_{2} \mathrm{H}_{5}^{+}$and $\mathrm{C}_{3} \mathrm{H}_{7}^{+}$, in concentrated than in ambient $\mathrm{HOA}$, shown as a larger $\mathrm{H}: \mathrm{C}$ for concentrated than for ambient HOA (Fig. 10). There could have been some mixing between HOA and OOAs in the PMF solution process, however, the average $\mathrm{H}: \mathrm{C}$ was larger for concentrated OA than for ambient OA probably due to the condensation of SVOCs or the growth of the small particles in the m-VACES, as discussed earlier.
The stability of the PMF solutions was tested by changing the fPEAK values in order to explore the possibility of local minima in the $\mathrm{Q}$ space. The fPEAK values of zero were chosen for both ambient and concentrated PMF solutions, being the minima in Q / Qexpected plots (Fig. S7 in the Supplement). For the ambient PMF solution Q / Qexpected was much lower $(\sim 0.5)$ than that for concentrated $(\sim 6)$, which indicates slight overestimation of error values for ambient data and larger signal-to-noise ratios for concentrated data. The influence of the fPEAK value $(-0.4-1.6)$ on the time series and mass spectra of PMF factors is presented in Fig. S8 in the Supplement. Time series and mass spectra of the PMF factors varied substantially with fPEAK. Both OOAs had large fluctuation, whereas the solution for HOA was more stable, especially for concentrated OA. Therefore, the difference in the PMF factors for ambient and concentrated OA could be caused mostly by the uncertainty in the PMF solution. It should be remembered here that the data set for the PMF analysis was very limited (less than 3 days), which could have affected the uncertainty in the PMF solutions.

\section{Summary and conclusions}

The performance of the m-VACES was investigated in laboratory and ambient atmospheres in Helsinki, Finland. The results of this study indicate that the m-VACES can be used together with advanced online instruments, such as the soot particle aerosol mass spectrometer, showing only minor artifacts associated with the particle size and chemical composition. The operation of the m-VACES was rather stable and reproducible, the enrichment process independent of the chemical nature of the particles. Commonly monitored inorganic gases $\left(\mathrm{O}_{3}, \mathrm{NO}, \mathrm{NO}_{2}, \mathrm{SO}_{2}\right.$ and $\left.\mathrm{CO}\right)$, ambient temperature or relative humidity did not correlate with any small fluctuations in the enrichment process and the enrichment efficiency was independent of species concentration levels. The small changes observed in the enrichment ratios seemed to be related to the variation of instrumental parameters in the m-VACES (e.g., saturator temperature).

The most significant artifact related to the operation of the m-VACES was the neutralization of acidic particles with gaseous ammonia and likely amines. One possibility to improve the performance of the m-VACES is to add denuders upstream of the concentrator, as suggested already for the VACES by Khlystov et al. (2005). The implementation of denuders could be easier for the m-VACES than for the VACES as the flow rate of the m-VACES is significantly lower.

In contrast to several other concentrator studies, there was no large artifact for OA in the m-VACES. The organic fraction showed similar enrichment efficiency with sulfate and nitrate, indicating artifacts only for hydrocarbons and nitrogen-containing organic components. Hydrocarbon fragments showed enhanced enrichment in the m-VACES, however, the amount of the hydrocarbon artifact was minor. 
Nitrogen-containing organics, most likely amines, induced much larger relative artifacts, but in their case the contribution to the total organic mass was small (3\% in the concentrated organics), so this artifact only represents a small perturbation of the overall properties of the aerosol, like the oxidation state. This is important when the chemical processing of aerosol is studied, e.g the aging process. Even though the properties of OA did not change substantially in the concentrating process, statistical analysis showed slightly different factors for ambient and concentrated OA. This may reflect the sensitivity of PMF to minor changes in the composition of OA, however, due to the small size of the data set used for the PMF analysis (3 days of data), the difference in the PMF factors for ambient and concentrated OA could also be caused by the uncertainty in the PMF solution.

The m-VACES is more suitable for the instruments that measure mass than for number-based online instruments. There is a shift in the size distribution for the small particles with sizes of up to $\sim 200 \mathrm{~nm}$ (mobility diameter) that has a much larger effect on particle number than on particle mass as the maximum in the number-size distribution is at a smaller size than in the mass-size distribution. For example, for the SP-AMS that measures mass, the shift in the size distribution only represented a small perturbation of the ambient aerosol.

Possible artifacts associated with the particle concentrators should always be studied carefully, as they may depend on the operational conditions and the ambient conditions and local properties of particles and gases (e.g., $\mathrm{NH}_{3}$ ), as observed here for acidic particles. Therefore, it should be noted that some of the results from the ambient measurements presented in this study may apply to the areas with conditions similar to those in Helsinki. Additional ambient tests are needed for the characterization of the m-VACES as the time period for the ambient measurements in this study was very limited (5 days).

\section{The Supplement related to this article is available online at doi:10.5194/amt-7-2121-2014-supplement.}

Acknowledgements. Sanna Saarikoski acknowledges the Academy of Finland for funding this study (grant no. 130695 and 259016) and Samara Carbone thanks the Graduate School in Physics, Chemistry, Biology and Meteorology of Atmospheric Composition and Climate Change (University of Helsinki) for funding. This work was also supported by the the Cluster for Energy and Environment (CLEEN Ltd) Measurement, Monitoring and Environmental Assessment (MMEA) work package 4.5.2. M. J. Cubison and J. L. Jimenez were supported by the NSF AGS1243354, NOAA NA13OAR4310063, and DOE (BER/ASR program) DE-SC0006035.

Edited by: P. Herckes

\section{References}

Aiken, A. C., DeCarlo, P. F., and Jimenez, J. L.: Elemental analysis of organic species with electron ionization high-resolution mass spectrometry, Anal. Chem., 79, 8350-8358, 2007.

Aiken, A. C., DeCarlo, P. F., Kroll, J. H., Worsnop, D. R., Huffman, J. A., Docherty, K., Ulbrich, I. M., Mohr, C., Kimmel, J. R., Sueper, D., Zhang, Q., Sun, Y., Trimborn, A., Northway, M., Ziemann, P. J., Canagaratna, M. R., Onasch, T. B., Alfarra, R., Prévôt, A. S. H., Dommen, J., Duplissy, J., Metzger, A., Baltensperger, U., and Jimenez., J. L.: O/C and OM/OC ratios of primary, secondary, and ambient organic aerosols with high resolution time-of-flight aerosol mass spectrometry. Environ. Sci. Technol., 42, 4478-4485, 2008.

Canagaratna, M. R., Jayne, J. T., Jimenez, J. L., Allan, J. D., Alfarra, M. R., Zhang, Q., Onasch, T. B., Drewnick, F., Coe, H., Middlebrook, A., Delia, A., Williams, L. R., Trimborn, A. M., Northway, M. J., DeCarlo, P. F., Kolb, C. E., Davidovits, P., and Worsnop, D. R.: Chemical and Microphysical Characterization of Ambient Aerosols with the Aerodyne Aerosol Mass Spectrometer, Mass Spectrom. Rev., 26, 185-222, 2007.

Chang, M. C., Sioutas, C., Kim, S., Gong Jr., H., and Linn, W. S.: Reduction of nitrate losses from filter and impactor samplers by means of concentration enrichment. Atmos. Environ., 34, 85-98, 2000.

Charlson, R. J., Schwartz, S. E., Hales, J. M., Cess, R. D., Coakley, J. A. Jr., Hasen, J. E., and Hofmann, D. J.: Climate Forcing by Anthropogenic Aerosols, Science, 255, 423-430, 1992.

Cho, A. K., Sioutas, C., Miguel, A. H., Kumagai, Y., Schmitz, D. A., Singh, M., Eiguren-Fernandez, A., and Froines, J. R.: Redox activity of airborne particulate matter at different sites in the Los Angeles Basin, Environ. Res., 99, 40-47, 2005.

DeCarlo P. F., Kimmel J. R., Trimborn A., Northway M. J., Jayne J. T., Aiken A. C., Gonin M., Fuhrer K., Horvath T., Docherty K. S., Worsnop D. R., and Jimenez J. L.: Field-deployable, highresolution, time-of-flight mass spectrometer, Anal. Chem., 78, 8281-8289, 2006.

Demokritou, P., Gupta, T. Ferguson, S., and Koutrakis, P.: Development of a High-Volume Concentrated Ambient Particles System (Caps) for Human and Animal Inhalation Toxicological Studies, Inhal. Toxicol., 15, 111-129, 2003.

Dockery, D. W., Pope, C. A., Xu, X., Spengler, J. D., Ware, J. H., Fay, M. E., Ferris, B. G., and Speizer, F. E.: An Association between Air Pollution and Mortality in Six US Cities, N. Engl. J. Med., 329, 1753-1759, 1993.

Dreyfus, M. A. and Johnston, M. V.: Rapid Sampling of Individual Organic Aerosol Species in Ambient Air with the Photoionization Aerosol Mass, Aerosol Sci. Technol., 42, 18-27, 2008.

Ellis, R. A., Murphy, J. G., Markovic, M. Z., VandenBoer, T. C., Makar, P. A., Brook, J., and Mihele, C.: The influence of gasparticle partitioning and surface-atmosphere exchange on ammonia during BAQS-Met, Atmos. Chem. Phys., 11, 133-145, doi:10.5194/acp-11-133-2011, 2011.

Freney, E. J., Heal, M. R., Donovan, R. J., Mills, N. L., Donaldson, K., Newby, D. E., Fokkens, P. HB., and Cassee, F. R.: A singleparticle characterization of a mobile Versatile Aerosol Concentration Enrichment System for exposure studies, Fibre Toxicol., 3, 8, doi:10.1186/1743-8977-3-8, 2006.

Geller, G. D., Biswas, S., Fine, P. M., and Sioutas, C.: A new compact aerosol concentrator for use in conjunction with low 
flow-rate continuous aerosol instrumentation, J. Aerosol Sci., 36, 1006-1022, 2005.

Gupta, T., Demokritou, P., and Koutrakis, P.: Development and Performance Evaluation of a High Volume Ultrafine Particle Concentrator for Inhalation Toxicological Studies, Inhal. Toxicol., 16, 1-12, 2004.

Huffman, J. A., Jayne, J. T., Drewnick, F., Aiken, A. C., Onasch, T., Worsnop, D. R., and Jimenez, J. L.: Design, Modeling, Optimization, and Experimental Tests of a Particle Beam Width Probe for the Aerodyne Aerosol Mass Spectrometer, Aerosol Sci. Technol., 39, 1143-1163, doi:10.1080/02786820500423782, 2005.

Järvi, L., Hannuniemi, H., Hussein, T., Junninen, H., Aalto, P. P., Hillamo, R., Mäkelä, T., Keronen, P., Siivola, E., Vesala, T., and Kulmala, M.: The urban measurement station SMEAR III: Continuous monitoring of air pollution and surface-atmosphere interactions in Helsinki, Finland, Boreal Environ. Res., 14, 86-109, 2009.

Jung, H., Arellanes, C., Zhao, Y., Paulson, S., Anastasio, C., and Wexler, A.: Impact of the Versatile Aerosol Concentration Enrichment System (VACES) on Gas Phase Species, Aerosol Sci. Technol., 44, 1113-1121, 2010.

Khlystov, A., Zhang, Q., Jimenez, J. L., Stanier, C., Pandis, S. N., Canagaratna, M. R., Fine, P., Misra, C., and Sioutas, C.: In situ concentration of semi-volatile aerosol using water-condensation technology, J. Aerosol Sci., 36, 866-880, 2005.

Kim, S., Jaques, P. A., Chang, M. C., Barone, T., Xiong, C., Friedlander, S. K., and Sioutas, C.: Versatile aerosol concentration enrichment system (VACES) for simultaneous in vivo and in vitro evaluation of toxic effects of ultrafine, fine and coarse ambient particles - Part II: field evaluation, J. Aerosol Sci., 32, 12991314, 2001a.

Kim, S., Jaques, P. A., Chang, M. C., Froines, J. R., and Sioutas, C.: Versatile aerosol concentration enrichment system (VACES) for simultaneous in vivo and in vitro evaluation of toxic effects of ultrafine, fine and coarse ambient particles - Part I: development and laboratory characterization, J. Aerosol Sci., 32, 1281-1297, $2001 b$.

Lanz, V. A., Alfarra, M. R., Baltensperger, U., Buchmann, B., Hueglin, C., and Prévôt, A. S. H.: Source apportionment of submicron organic aerosols at an urban site by factor analytical modelling of aerosol mass spectra, Atmos. Chem. Phys., 7, 15031522, doi:10.5194/acp-7-1503-2007, 2007.

Lee, T., Sullivan, A. P., Mack, L., Jimenez, J. L., Kreidenweis, S. M. Onasch, T. B., Worsnop, D. R., Malm, W., Wold, C. E., Hao, W. M., and Collett Jr., J. L.: Chemical smoke marker emissions during flaming and smoldering phases of laboratory open burning of wildland fuels, Aerosol Sci. Technol., 44, i-v, 2010.

Massoli, P., Fortner, E. C., Canagaratna, M. R., Williams, L. R., Zhang, Q., Sun, Y., Schwab, J. J., Trimborn, A., Onasch, T. B., Demerjian, K. L., Kolb, C. E., Worsnop, D. R., and Jayne, J. T.: Pollution Gradients and Chemical Characterization of Particulate Matter from Vehicular Traffic near Major Roadways: Results from the 2009 Queens College Air Quality Study in NYC, Aerosol Sci. Technol., 46, 1201-1218, 2012.

Matthew, B. M., Middlebrook, A. M., and Onasch, T. B.: Collection Efficiencies in an Aerodyne Aerosol Mass Spectrometer as a Function of Particle Phase for Laboratory Generated Aerosols, Aerosol Sci. Technol., 42, 884-898, doi:10.1080/02786820802356797, 2008.
McWhinney, R. D., Rastogi, N., Urch, B., Silverman, F., Brook, J. R., Evans, G. J., and Abbatt, J. P. D.: Characterization of the University of Toronto Concentrated Aerosol Particle Exposure Facility (CAPEF) - Effects on Fine and Ultrafine Nonrefractory Aerosol Composition, Aerosol Sci. Technol., 46, 697-707, 2012.

Ning, Z., Moore, K. F., Polidori, A., and Sioutas, C.: Field Validation of the New Miniature Versatile Aerosol Concentration Enrichment System (mVACES), Aerosol Sci. Technol., 40, 10981110, 2006.

Onasch, T. B., Trimborn, A., Fortner, E. C., Jayne, J. T., Kok, G. L., Williams, L. R., Davidovits, P., and Worsnop, D. R.: Soot Particle Aerosol Mass Spectrometer: Development, Validation, and Initial Application, Aerosol Sci. Technol., 46, 804-817, 2012.

Paatero, P. and Tapper, U.: Positive Matrix Factorization - a Nonnegative Factor Model with Optimal Utilization of ErrorEstimates of Data Values, Environmetrics, 5, 111-126, 1994.

Ramanathan, V. and Carmichael, G.: Global and regional climate changes due to black carbon, Nat. Geosci., 1, 221-227, 2008.

Rastogi, N., McWhinney, R. D., Akhtar, U. S., Urch, B., Fila, M., Abbatt, J. P. D., Scott, J. A., Silverman, F., Brook, J. R., and Evans, G. J.: Physical characterization of the University of Toronto Coarse, Fine and Ultrafine High-Volume Particle Concentrator Systems, Aerosol Sci. Technol., 46, 1015-1024, 2012.

Saarikoski, S., Timonen, H., Saarnio, K., Aurela, M., Järvi, L., Keronen, P., Kerminen, V.-M., and Hillamo, R.: Sources of organic carbon in fine particulate matter in northern European urban air, Atmos. Chem. Phys., 8, 6281-6295, doi:10.5194/acp-86281-2008, 2008.

Saarnio, K., Aurela, M., Timonen, H., Saarikoski, S., Teinilä, K., Mäkelä, T., Sofiev, M., Koskinen, J., Aalto, P. P., Kulmala, M., Kukkonen, J., and Hillamo, R.: Chemical composition of fine particles in fresh smoke plumes from boreal wild-land fires in Europe, Sci. Total Environ., 408, 2527-2542, 2010.

Salcedo, D., Onasch, T. B., Aiken, A. C., Williams, L. R., de Foy, B., Cubison, M. J., Worsnop, D. R., Molina, L. T., and Jimenez, J. L.: Determination of particulate lead using aerosol mass spectrometry: MILAGRO/MCMA-2006 observations, Atmos. Chem. Phys., 10, 5371-5389, doi:10.5194/acp-10-5371-2010, 2010.

Salcedo, D., Laskin, A., Shutthanandan, V., and Jimenez, J.-L.: Feasibility of the Detection of Trace Elements in Particulate Matter Using Online High-Resolution Aerosol Mass Spectrometry, Aerosol Sci. Technol., 46, 1187-1200, 2012.

Sioutas, C., Koutrakis, P., Godleski, J. J., Ferguson, S. T., Kim, C. S., and Burton, R. M.: Fine particle concentrators for inhalation exposures - effect of particle size and composition, J. Aerosol Sci., 28, 1057-1071, 1997.

Smith, J. N., Barsanti, K. C., Friedli, H. R., Ehn, M., Kulmala, M., Collins, D. R., Scheckman, J. H., Williams, B. J., and McMurry, P. H.: Observations of aminium salts in atmospheric nanoparticles and possible climatic implications, Proc. Natl. Aca. Sci., 107, 6634-6639, 2010.

Su, Y., Sipin, M. F., Spencer, M. T., Qin, X., Moffet, R. C., Shields, L. G., Prather, K. A., Venkatachari, P., Jeong, C.-H., Kim, E., Hopke, P. K., Gelein, R. M., Utell, M. J., Oberdörster, G., Berntsen, J., Devlin, R. B., and Chen, L. C.: Real-Time Characterization of the Composition of Individual Particles Emitted From Ultrafine Particle Concentrators, Aerosol Sci. Technol., 40, 437-455, 2006. 
Sun, Y., Zhang, Q., Macdonald, A. M., Hayden, K., Li, S. M., Liggio, J., Liu, P. S. K., Anlauf, K. G., Leaitch, W. R., Steffen, A., Cubison, M., Worsnop, D. R., van Donkelaar, A., and Martin, R. V.: Size-resolved aerosol chemistry on Whistler Mountain, Canada with a high-resolution aerosol mass spectrometer during INTEX-B, Atmos. Chem. Phys., 9, 3095-3111, doi:10.5194/acp9-3095-2009, 2009.

Timonen, H., Saarikoski, S., Tolonen-Kivimäki, O., Aurela, M., Saarnio, K., Petäjä, T., Aalto, P. P., Kulmala, M., Pakkanen, T., and Hillamo, R.: Size distributions, sources and source areas of water-soluble organic carbon in urban background air, Atmos. Chem. Phys., 8, 5635-5647, doi:10.5194/acp-8-5635-2008, 2008.

Ulbrich, I. M., Canagaratna, M. R., Zhang, Q., Worsnop, D. R., and Jimenez, J. L.: Interpretation of organic components from Positive Matrix Factorization of aerosol mass spectrometric data, Atmos. Chem. Phys., 9, 2891-2918, doi:10.5194/acp-9-2891-2009, 2009.
Wang, D., Pakbin, P, Saffari, A., Shafer, M. M., Schauer, J. J., and Sioutas, C.: Development and Evaluation of a HighVolume Aerosol-into-Liquid Collector for Fine and Ultrafine Particulate Matter, Aerosol Sci. Technol., 47, 1226-1238, doi:10.1080/02786826.2013.830693, 2013.

Willeke, K. and Baron, P. A.: Aerosol measurement: principles, techniques, and applications, New York, Van Nostrand Reinhold, 1993.

Zhao, Y., Bein, K. J., Wexler, A. S., Misra, C., Fine, P. M., and Sioutas, C.: Field evaluation of the versatile aerosol concentration enrichment system (VACES) particle concentrator coupled to the rapid single-particle mass spectrometer (RSMS-3), J. Geophys. Res., 110, D07S02, doi:10.1029/2004JD004644, 2005. 